Article

\title{
HPLC with Fluorescence Detection for Determination of Bisphenol A in Canned Vegetables: Optimization, Validation and Application to Samples from Portuguese and Spanish Markets
}

\author{
Fernanda Vilarinho ${ }^{1} \mathbb{D}$, Antia Lestido-Cardama ${ }^{2} \mathbb{C}$, Raquel Sendón ${ }^{2}{ }^{\mathbb{D}}$, \\ Ana Rodríguez Bernaldo de Quirós ${ }^{2}$, Maria de Fátima Vaz $^{3} \mathbb{D}$ and Ana Sanches-Silva ${ }^{4,5, *(\mathbb{D})}$ \\ 1 Department of Food and Nutrition, National Institute of Health Dr. Ricardo Jorge, I.P., \\ 1600-560 Lisbon, Portugal; fernanda.vilarinho@insa.min-saude.pt \\ 2 Department of Analytical Chemistry, Nutrition and Food Science, Pharmacy Faculty, \\ University of Santiago de Compostela, 15705 Santiago de Compostela, Spain; antia.lestido@usc.es (A.L.-C.); \\ raquel.sendon@usc.es (R.S.); ana.rodriguez.bernaldo@usc.es (A.R.B.d.Q.) \\ 3 IDMEC, Instituto Superior Técnico, Departamento de Engenharia Mecânica, University of Lisbon, \\ 1649-004 Lisbon, Portugal; fatima.vaz@tecnico.ulisboa.pt \\ 4 National Institute for Agricultural and Veterinary Research (INIAV), 2780-157 Vairão, Portugal \\ 5 Center for Study in Animal Science (CECA), ICETA, University of Porto, 4099-002 Porto, Portugal \\ * Correspondence: ana.silva@iniav.pt
}

Received: 9 June 2020; Accepted: 29 June 2020; Published: 30 June 2020

\begin{abstract}
Bisphenol A (BPA) is one of the chemicals used to produce both polycarbonate plastics and epoxy resin coatings. Research has shown that small amounts of BPA can migrate into the foods and beverages enclosed in these types of containers. In this research, an analytical method based on high-performance liquid chromatography with fluorescence detection (HPLC-FLD) was developed and validated for the determination of BPA in canned vegetables. The results were confirmed by liquid chromatography coupled to tandem mass spectrometry (LC-MS/MS). Attenuated total reflectance Fourier transform infrared spectroscopy (ATR-FTIR) was performed, to identify the coating material of each tin can. Nineteen cans of vegetables were taken as study samples (eleven samples from the Spanish market, and eight samples from the Portuguese market). Excellent linear correlation $\left(r^{2}=0.9999\right)$ was observed over the range of 0.01 to $0.25 \mathrm{mg} / \mathrm{L}$. Limit of detection (LOD) and limit of quantification (LOQ) values were calculated to be $0.005 \mathrm{mg} / \mathrm{kg}$ and $0.01 \mathrm{mg} / \mathrm{kg}$, respectively. Good recoveries, between $72 \%$ and $90 \%$ were obtained at three different levels of concentration (RSD $\%=4.6$ ). BPA was not detected in the samples. The proposed HPLC-FLD was found to be suitable for the determination of BPA in canned vegetables.
\end{abstract}

Keywords: bisphenol A; epoxy resins; canned vegetables; HPLC-FLD; LC-MS/MS

\section{Introduction}

People are exposed to contaminants through several sources. Packaging can be a potential source of contamination through the migration of substances from the packaging material into the food [1]. This fact is especially relevant, as most of the food found at the supermarkets is packaged in order to prevent its deterioration and to extend its shelf life [1-3] In order to ensure food safety, the monitoring of migration from food contact materials has become a priority issue. For researchers, the study of the contaminant bisphenol A (BPA) and its impact on the endocrine system are of major concern, because BPA exhibits estrogenic properties arising from its structural resemblance to the human $17 \beta$-estradiol [4] and disturbs the endocrine and reproductive systems [5-7]. 
Bisphenol A [2,2-bis(4 hydroxyphenyl)propane] has the chemical formula $\mathrm{C}_{15} \mathrm{H}_{16} \mathrm{O}_{2}$ and results from the condensation of $2 \mathrm{~mol}$ of phenol with $1 \mathrm{~mol}$ of acetone in the presence of an acid catalyst [4].

BPA is mainly (approximately 95\%) used in the production of synthetic polymers including epoxy resins (as the internal coating of food and beverage cans) and polycarbonates (storage containers, reusable plastic bottles, plates, among others) [2,4]. BPA is also used in the production of plasticized PVC as inhibitor of the polymerization of vinyl chloride and, in some plasticizers as antioxidant [8].

With several limitations, BPA is authorized to be used as a monomer in the manufacture of plastic materials intended to come into contact with food in the European Union. According to Regulation (EU) no. 10/2011 [9] and its amendments, BPA has a specific migration limit of $0.05 \mathrm{mg} / \mathrm{kg}$ [10]. Moreover, BPA is not authorized to be used for the manufacture of polycarbonate infant feeding bottles [11] and polycarbonate drinking cups or bottles which, due to their spill proof characteristics, are intended for infants and young children (Regulation (EU) no. 2018/213) [10].

In recent years many methods for measuring the BPA in food have been developed. In 2019 F. Vilarinho et al. [4] carried out an exhaustive compilation and discussion of the analytical methodologies used for the determination of BPA as result of its migration from food contact materials. The determination of BPA in food is mainly performed by liquid chromatography (LC) $[4,12,13]$ with different detectors: ultraviolet (LC/UV) [14], fluorescence (LC/FLD), electrochemical detection (LC/ECD), mass spectrometry (LC/MS), and tandem mass spectrometry (LC/MS-MS) [15] or by gas chromatography (GC) coupled with mass spectrometry (GC/MS) and tandem mass spectrometry (GC/MS-MS) $[4,13,16]$. According to Vilarinho et al. [4] the MS detector is the most usually used for both LC and GC, due to its unquestionable advantages which comprehend high selectivity, high sensitivity, and universality. It is important to notice that the choice of the detector, greatly influences the detection limit (LOD) and the quantification limit (LOQ) [4].

In the present study, the development and validation of an analytical method by high-performance liquid chromatography with fluorescence detection (HPLC-FLD) to quantify BPA in canned vegetables are reported. The liquid chromatography-tandem mass spectrometry (LC-MS/MS) was used to confirm the results obtained. Attenuated total reflectance Fourier transform infrared spectroscopy (ATR-FTIR) was performed to identify the coating material of each of cans of samples selected for the study. Nineteen canned vegetables (eleven samples from the Spanish market, and eight samples from the Portuguese market) were evaluated in order to check their compliance with the legislation in force in the European Union.

\section{Materials and Methods}

\subsection{Chemicals and Standard Solutions}

All reagents were analytical grade. Acetonitrile LC Grade (Lichrosolv, Merck KGaA, Darmstadt, Germany). Methanol LC-MS Grade was provided from Merck (Darmstadt, Germany). Ultrapure water (type I) was obtained from an Automatic Plus purification system (Wasserlab, Navarra, Spain). Standard Bisphenol A (BPA; 2,2-bis(4-hydroxyphenyl)propane; 4,4'-isopropylidene-diphenol), with a purity $>99 \%$ was acquired from Aldrich-Chemie (Steinheim, Germany).

BPA stock solution was prepared by dissolving the BPA in acetonitrile (ACN) in order to obtain $1000 \mathrm{mg} \mathrm{L}^{-1}$. Standard solutions of concentration between 0.005 and $0.25 \mathrm{mg} \mathrm{L}^{-1}$ were prepared by diluting the stock solution with the ACN/Water (10:90).

\subsection{Samples Preparation}

Nineteen commercial canned vegetables were purchased in three different local supermarkets of Lisbon (Portugal) and Santiago de Compostela (Spain). The canned samples have different food products: namely, three samples of canned fine peas, two of artichoke hearts, two of sweet corn, one of chilli peppers, one of asparagus (thick gauge), one of red peppers-all natural, one of rolled mushrooms, one of Almagro eggplant, one of whole peeled tomato, one of white cabbage, one of cooked 
lentils, one of vegetables of Macedonia, one of mung bean sprouts and two of green beans (Table 1). All canned foodstuffs were sampled in duplicate, therefore the result is the mean of two independent measurements Samples were stored at room temperature until analysis.

Table 1. Samples selected for the present study (P-Portugal; E-Spain).

\begin{tabular}{cc}
\hline Origin (Country) & Samples Used for Trial \\
\hline $1 \mathrm{E}$ & Alegrias Riojanas \\
$2 \mathrm{E}$ & Asparagus buds \\
$3 \mathrm{E}$ & Red peppers-whole in brine \\
$4 \mathrm{E}$ & Artichoke hearts \\
$5 \mathrm{E}$ & Sweet corn \\
$6 \mathrm{E}$ & Peas with extra-fine carrots \\
$7 \mathrm{E}$ & Laminated mushrooms \\
$8 \mathrm{E}$ & Eggplant Almagro \\
$9 \mathrm{E}$ & Fine peas \\
$10 \mathrm{E}$ & Whole peeled tomato \\
$11 \mathrm{E}$ & White cabbage \\
$1 \mathrm{P}$ & Very fine peas \\
$2 \mathrm{P}$ & Cooked lentils \\
$3 \mathrm{P}$ & Vegetables of Macedonia \\
$4 \mathrm{P}$ & Sweet corn \\
$5 \mathrm{P}$ & Mungo bean sprouts \\
$6 \mathrm{P}$ & White cooked quinoa \\
$7 \mathrm{P}$ & Green beans \\
$8 \mathrm{P}$ & Artichoke Hearts \\
\hline
\end{tabular}

Following the preparation of foods described by Nerín et al. (2002) [17] and because the objective of the paper was also to first screen BPA in canned vegetables, the liquid phase in contact with canned foods was analyzed. To determine the amount of BPA present in each sample, the net content of each can was leaked into a container. Then $900 \mu \mathrm{L}$ were removed from this container and $100 \mu \mathrm{L}$ of can was added. This mixture was filtered and then injected into HPLC-FLD and LC-MS/MS.

\subsection{HPLC-FLD}

The high-performance liquid chromatography (HPLC) system used in this study was an Agilent Technologies 1200 Series (Waldbronn, Germany) constituted by a quaternary pump, a degassing device, an autosampler, a column thermostat system, a diode array detector, a fluorescence detector and an Agilent ChemStation for LC and ChemStation for LC 3D Systems software (version B.04.0x).

\subsection{LC-MS/MS}

The liquid chromatography-tandem mass spectrometry (LC-MS/MS) system used in this study consisted of an Accela autosampler, a column thermostat system and Accela 1250 pump fitted with a degasser, coupled to a TSQ Quantum Access Max Triple Quadrupole controlled by Xcalibur 2.1.0 (Thermo Fisher Scientific, San José, CA, USA). MS data were acquired in the negative Atmospheric Pressure Chemical Ionization (APCI) mode. The operating conditions were: spray voltage $2500 \mathrm{~V}$; nebulizer gas $\left(\mathrm{N}_{2}\right), 35 \mathrm{psi}$; vaporizer temperature $400^{\circ} \mathrm{C}$; capillary temperature $350{ }^{\circ} \mathrm{C}$. As the collision gas was used Argon (1.5 mTorr). The selected precursor ion for BPA was m /z 227.2 and the two SRM transitions monitored were 227.2-212.1 and 227.2-133.2 m/z with a collision energy of 21 and $29 \mathrm{~V}$ respectively (Table 3).

\subsection{Chromatographic Conditions}

The chromatographic conditions for the HPLC-FLD and the LC-MS/MS analyses are similar. Table 2 shows the chromatographic conditions for BPA separation/quantification and Table 3 indicates 
the gradient elution conditions [18]. For LC-MS/MS analysis the organic solvent used was methanol instead of acetonitrile.

Table 2. Chromatographic conditions for the determination of bisphenol A (BPA) as results of its migration to canned vegetables.

\begin{tabular}{cc}
\hline \multicolumn{2}{c}{ Chromatographic Conditions of HPLC-FLD and LC-MS/MS Methods } \\
\hline Analytical column & Luna $^{\circledR} \mathrm{C} 18(2) 100 \AA(150 \mathrm{~mm} \times 3 \mathrm{~mm}, 5 \mu \mathrm{m}$ particle size $)$ \\
\hline Temperature & $2{ }^{\circ} \mathrm{C}$ \\
\hline Injection volume & $20 \mu \mathrm{l}$ \\
\hline FLD detector & MS spectrometer conditions \\
\hline & Negative atmospheric pressure chemical ionization $(\mathrm{APCI})$ mode \\
\hline Acquired in & $2500 \mathrm{~V}$ \\
\hline Spray voltage & $\left(\mathrm{N}_{2}\right), 35 \mathrm{psi}$ \\
\hline Nebulizer gas & $400{ }^{\circ} \mathrm{C}$ \\
\hline Vaporizer temperature & $350{ }^{\circ} \mathrm{C}$ \\
\hline Capillary temperature & Argon $(1.5 \mathrm{mTorr})$ \\
\hline Collision gas & $\mathrm{m} / \mathrm{z} 227.2$ \\
\hline Selected precursor ion for BPA & $227.2>212.1$, collision energy: $21 \mathrm{~V}$ \\
\hline SRM transitions monitored & $227.2 .>133.2$, collision energy: $29 \mathrm{~V}$ \\
\hline SRM transitions monitored &
\end{tabular}

Table 3. Gradient elution conditions of HPLC-FLD and LC-MS/MS methods.

\begin{tabular}{ccc}
\hline Time (min) & \%A & \%B \\
\hline 0.0 & 70.0 & 30.0 \\
2.00 & 70.0 & 30.0 \\
23.00 & 0.0 & 100.0 \\
30.00 & 0.0 & 100.0 \\
32.00 & 70.0 & 30.0 \\
35.00 & 70.0 & 30.0 \\
\hline
\end{tabular}

${ }^{*} \mathrm{~B}$ corresponds to acetonitrile in HPLC-FLD or methanol in LC-MS/MS.

\subsection{ATR-FTIR}

Infrared spectra were acquired using an ATR-FTIR spectrometer (ATR-PRO ONE FT-IR4700, Jasco, Japan) equipped with a Diamond optical element (in the range from $4000-650 \mathrm{~cm}^{-1}$ ). ATR-FTIR spectrometer was controlled by the software Spectra Manager ${ }^{\mathrm{TM}}$ Suite (version 2). The identification was carried out by using the IR Spectral libraries of Polymers \& Related Compounds (Bio-Rad Laboratories, Inc., Hercules, CA, USA) using the software KnowItAll ${ }^{\circledR}$ (version 17.4.135.B).

\subsection{Recovery}

To determine recovery of BPA, a spiking experiment using a canned vegetable BPA free (blank) was performed. The spiking levels chosen were $0.01,0.05$ and $0.25 \mathrm{mg} \mathrm{kg}^{-1}$ of BPA, respectively. HPLC results were plotted into the BPA calibration curve. Spiking assays were performed by different operators, in three different days and the recovery was calculated by comparing the theoretical spiking and practical BPA value obtained from HPLC. 


\subsection{Precision}

Repeatability and precision were determined by running spiking experiments on a representative sample at 3 different spiking levels $\left(0.01,0.05\right.$ and $\left.0.25 \mathrm{mg} \mathrm{kg}^{-1}\right)$. Repeatability was carried out in a single day and precision (internal reproducibility) was performed during three different days and with different operators. Data are expressed in terms of \% of relative standard deviation (\%RSD).

\section{Results and Discussion}

\subsection{Method Validation}

Validation parameters including linearity, precision (internal reproducibility), limit of detection (LOD) and limit of quantification (LOQ) were determined according to the International Conference on Harmonisation (ICH) guidelines Q2 (R1) [19,20].

The use of a series of standards solutions of known concentration allowed to test the linearity of the method. The calibrations curves were constructed using six concentration levels $(0.005,0.010$, $0.025,0.050,0.100$ and $0.250 \mathrm{mg} \mathrm{L}^{-1}$ ) and they were fitted to a linear equation. The linearity was tested in acetonitrile/water $(10: 90, \mathrm{v} / \mathrm{v})$ as solvent. Three calibration curves were performed in three different days. All of them have shown good linearity in the studied concentration range with coefficients of determination $\left(r^{2}\right)$ equal to 0.9999 , indicating suitability for BPA quantification in the selected calibration range. Table 4 shows the parameters of linearity.

Table 4. Recovery, repeatability and intermediate precision of the HPLC-FLD method.

\begin{tabular}{|c|c|c|c|c|c|c|c|c|c|}
\hline \multirow{2}{*}{$\begin{array}{c}\text { Compound } \\
\text { BPA }\end{array}$} & \multicolumn{3}{|c|}{$\begin{array}{l}\text { Recovery }(\%) \\
(n=6)\end{array}$} & \multicolumn{3}{|c|}{$\begin{array}{c}\text { Repeatability (RSD \%) } \\
\qquad(n=6)\end{array}$} & \multicolumn{3}{|c|}{$\begin{array}{l}\text { Intermediate Precision (RSD\%) } \\
(n=18)\end{array}$} \\
\hline & $\begin{array}{c}0.01^{\mathrm{a})} \\
\mathrm{mg} \mathrm{kg}^{-1}\end{array}$ & $\begin{array}{c}0.05^{\text {a) }} \\
\mathrm{mg} \mathrm{kg}^{-1}\end{array}$ & $\begin{array}{c}0.25^{\text {a) }} \\
\mathrm{mg} \mathrm{kg}^{-1}\end{array}$ & $\begin{array}{c}0.01^{\text {a) }} \\
\mathrm{mg} \mathrm{kg}^{-1}\end{array}$ & $\begin{array}{c}0.05^{\text {a) }} \\
\mathrm{mg} \mathrm{kg}^{-1}\end{array}$ & $\begin{array}{c}0.25^{\text {a) }} \\
\mathrm{mg} \mathrm{kg}^{-1}\end{array}$ & $\begin{array}{c}0.01^{\text {a) }} \\
\mathrm{mg} \mathrm{kg}^{-1}\end{array}$ & $\begin{array}{c}0.05^{\text {a) }} \\
\mathrm{mg} \mathrm{kg}^{-1}\end{array}$ & $\begin{array}{c}0.25^{\text {a) }} \\
\mathrm{mg} \mathrm{kg}^{-1}\end{array}$ \\
\hline & 90 & 77 & 72 & 9.94 & 3.48 & 3.26 & 4.53 & 4.70 & 0.57 \\
\hline
\end{tabular}

The limits of detection and quantification, calculated according to ACS guidelines [21] (defined as three and ten times the height signal of the noise level, respectively) were presented in Table 5. The method presents enough sensitivity to detect the BPA at the regulatory level, once the experimental LOD $\left(0.005 \mathrm{mg} \mathrm{kg}^{-1}\right)$ is considerably lower than the specific migration limit (SML) of $0.05 \mathrm{mg} \mathrm{kg}^{-1} \mathrm{established}^{-}$ by the Regulation (EU) no. 10/2011 and its amendments, which are in force $[4,10]$.

Table 5. Linearity, limit of detection and quantification of BPA according to the International Conference on Harmonisation (ICH) guidelines Q2 (R1), and using high-performance liquid chromatography (HPLC) with fluorescence detection (FLD).

\begin{tabular}{|c|c|c|c|c|c|}
\hline Day & Equation & $r^{2}$ & LOD (mg kg $\left.{ }^{-1}\right)$ & LOQ (mg kg $\left.{ }^{-1}\right)$ & Range (mg kg ${ }^{-1}$ ) \\
\hline 1 & $y=224.71 x-0.1121$ & \multirow{3}{*}{0.9999} & \multirow{3}{*}{0.005} & \multirow{3}{*}{0.01} & \multirow{3}{*}{$0.01-0.25$} \\
\hline 2 & $y=223.92 x-0.2539$ & & & & \\
\hline 3 & $y=219.54 x-0.113$ & & & & \\
\hline
\end{tabular}

Figure 1 shows the chromatogram obtained by HPLC-FLD with $0.005 \mathrm{mg} \mathrm{kg}^{-1}$ standard solution, that is the limit of detection of the method.

As an important step in the validation process, is to demonstrate that the proposed methodology is fit to its purpose. This was evaluated through recovery assays, spiking a BPA free-sample. A working session with six replicates for each spiking level was performed in three different days. According to the results report in Table 4, it is confirmed that the method internal reproducibility is appropiate even at low concentrations, with average recoveries $(n=18)$ ranging from $72 \%$ to $90 \%$. Repeatability 
was always lower than $3.48 \%$, except at $0.01 \mathrm{mg} \mathrm{kg}^{-1}$, which was $9.94 \%$, and intermediate precision was always lower than $4.70 \%$, indicating good precision. Poustka et al. (2007) [22] in their research, reported the results of bisphenols monitoring in various categories of canned food obtained from the Czech retail market through the validation of analytical procedure HPLC coupled with FLD. They obtained recoveries, not below 75\%, and LOD and LOQ of 0.002 and $0.01 \mathrm{mg} \mathrm{kg}^{-1}$, respectively. In its turn, Errico et al. (2014) [23] in its work performed the determination of bisphenol A (BPA) in canned tomatoes by a method based on solid-phase extraction followed by liquid chromatography coupled to fluorescence spectrophotometry obtaining a LOQ of $0.26 \mu \mathrm{g} \mathrm{BPA} \mathrm{kg}{ }^{-1}$ tomato.

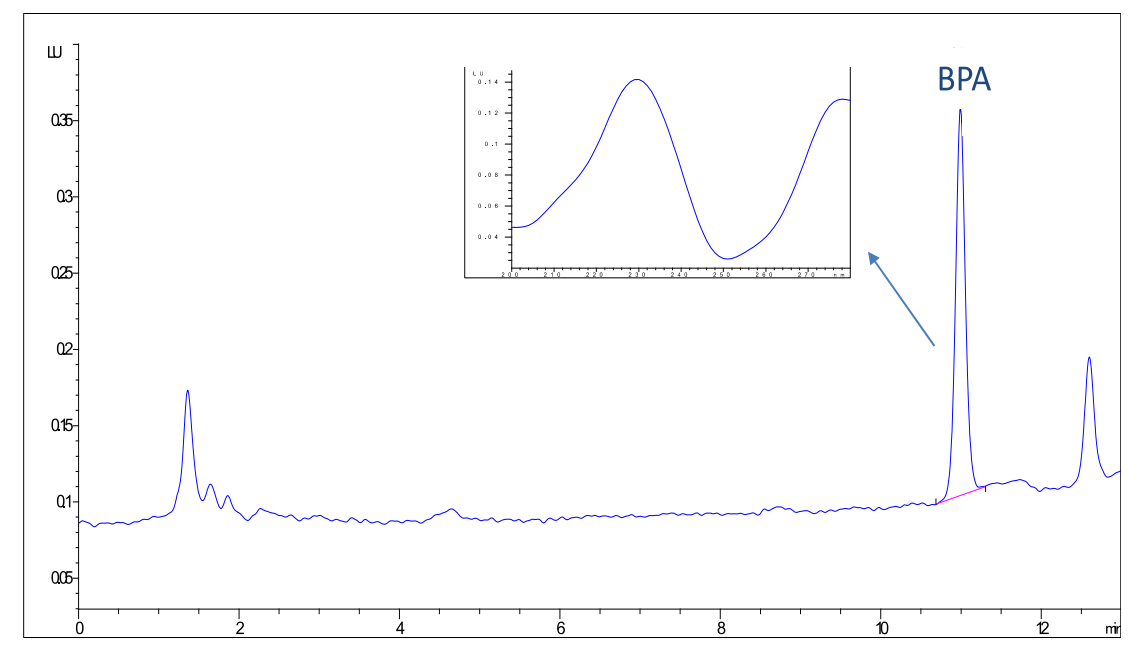

Figure 1. Chromatograms obtained by HPLC-FLD with a $0.005 \mathrm{mg} \cdot \mathrm{kg}^{-1}$ standard solution: luminescence units (LU) vs. retention time ( $\mathrm{min})$.

Figures 2 and 3 show the chromatogram obtained by HPLC-FLD with a fortification level of $0.01 \mathrm{mg} \mathrm{kg}^{-1}$ and a chromatogram obtained by HPLC-FLD of a sample of "sweet corn" where BPA was not detected, respectively.

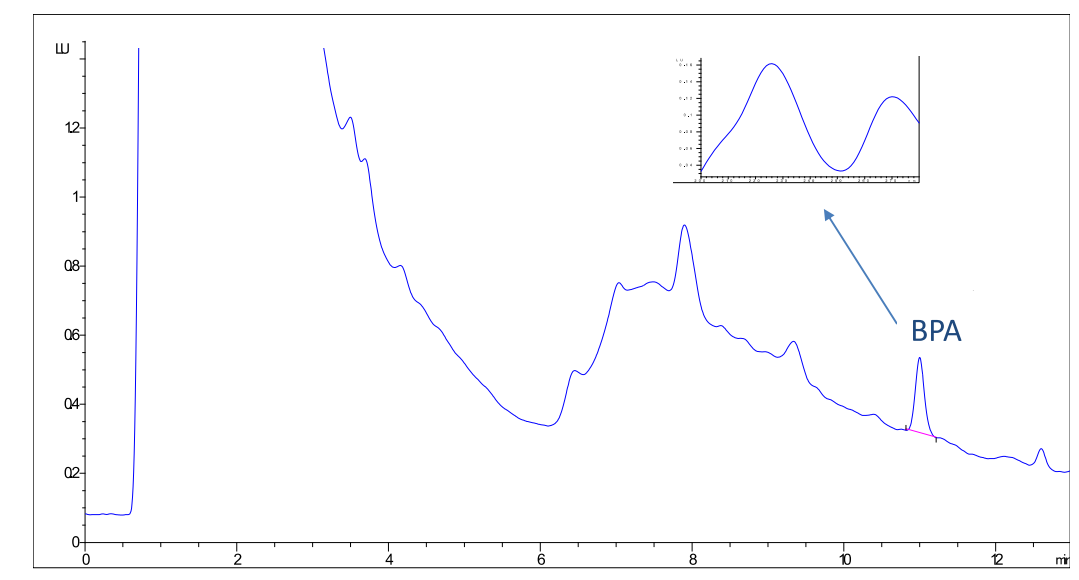

Figure 2. HPLC-FLD chromatogram of a blank sample ("sweet corn") with a fortification level of $0.01 \mathrm{mg} \mathrm{kg}^{-1}$. Luminescence unit (LU) vs Retention Time (min).

\section{2. $L C-M S / M S$}

In order to optimize and obtain the appropriate signal response in LC-MS/MS, acetonitrile and methanol were introduced as mobile phases. The best signal was achieved with methanol-water as a mobile phase. 
MS data were acquired in selected reaction monitoring (SRM) mode once the optimization of the MS/MS parameters was performed using the built-in perfusion system. The ion $\mathrm{m} / \mathrm{z} 227.2$ has been assigned as the deprotonated molecule $[\mathrm{M}-\mathrm{H}]^{-}$, the transition $\mathrm{m} / \mathrm{z} 227.2>212.1$ was related with the additional loss of oxygen $[\mathrm{M}-\mathrm{H}-\mathrm{O}]^{-}$and the transition $\mathrm{m} / \mathrm{z} 227.2>133.2$ with the loss of phenol group [4].

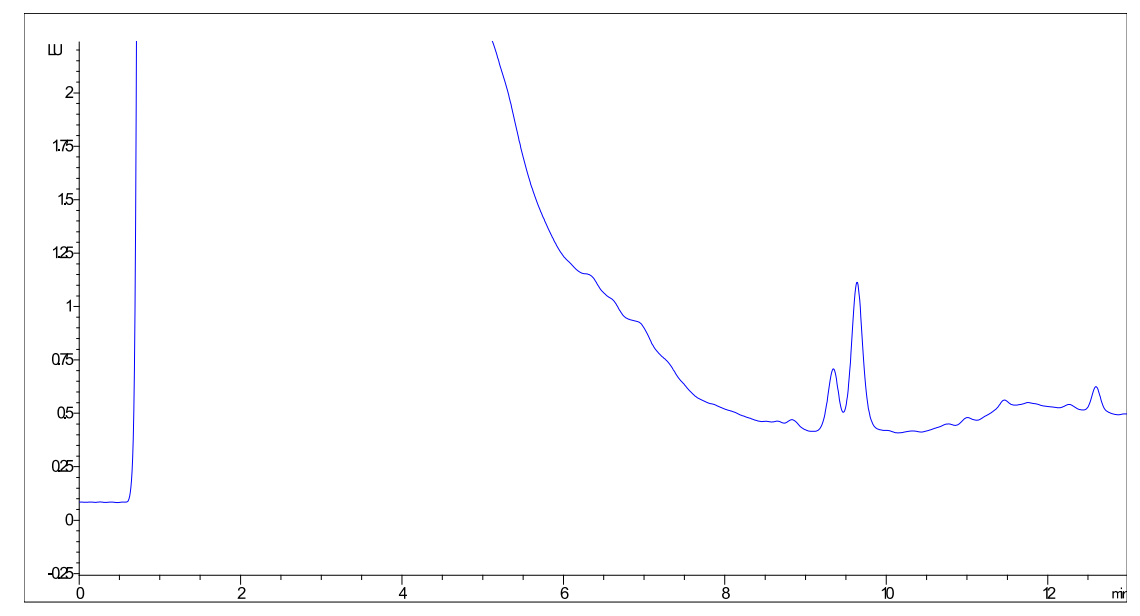

Figure 3. Chromatogram obtained by HPLC-FLD with a blank sample of "sweet corn": luminescence unit (LU) vs. retention time (min).

LC-MS/MS is valuable to confirm the results of HPLC-FLD. However, this technique has a higher LOD $\left(0.01 \mathrm{mg} \mathrm{kg}^{-1}\right)$ than HPLC-FLD $\left(0.005 \mathrm{mg} \mathrm{kg}^{-1}\right)$. The Figure 4 shows the chromatogram obtained by LC-MS/MS for the $0.01 \mathrm{mg} \mathrm{kg}^{-1}$ standard solution of the BPA.

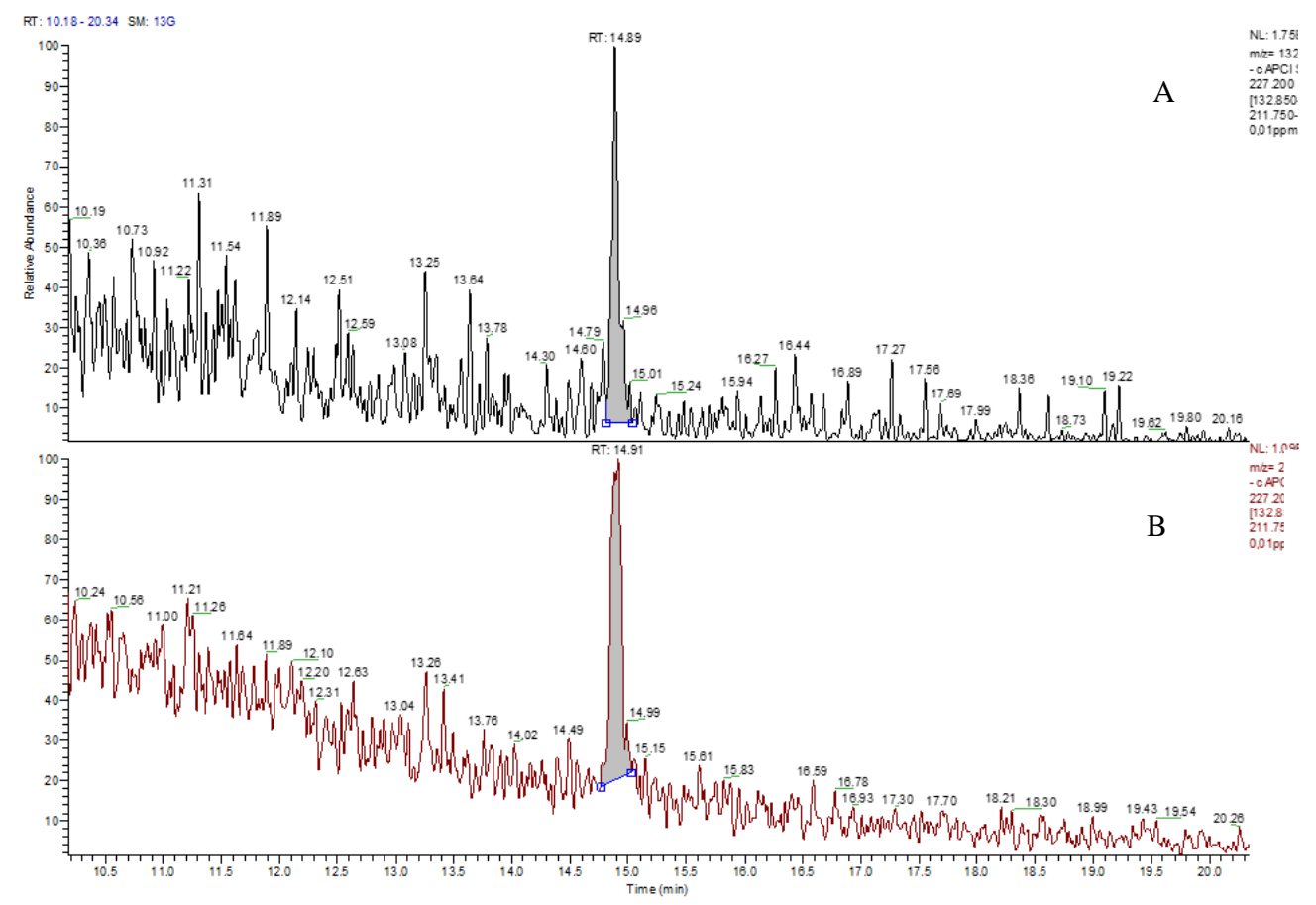

Figure 4. Chromatograms obtained by LC-MS/MS for the $0.01 \mathrm{mg} \mathrm{kg}^{-1}$ standard solution of the BPA: (A) the transition $227.2>133.1 \mathrm{~m} / \mathrm{z}$; (B) the transition $227.2>212.1 \mathrm{~m} / \mathrm{z}$. 
In our study, any of the samples presented detectable BPA according to HPLC-FLD, therefore it was not necessary to analyse them by LC-MS/MS. However, we decided to analyse the samples by LC-MS/MS and also none of them showed detectable amounts of BPA by this technique.

\subsection{ATR-FTIR}

For the analysis of the cans by ATR-FTIR, small pieces of each sample (can) were cut with an area suitable to be used in the spectrophotometer. Pieces of the cover, bottom and side of each tin can were analyzed. Subsequently, each piece of the sample was analyzed by ATR-FTIR regarding their inner part. The identification was carried out by comparing obtained spectra with those of the IR Spectral libraries of Polymers and Related Compounds (Bio-Rad Laboratories, Inc.) database.

Analyzing the results listed in Table 6, it can be seen that polyester, phenoxy and epoxy coatings are those that are used in the samples. However, the polyester is the most used, as $78 \%$ of the samples have a polyester coating. Figure 5 shows, as an example, two spectra obtained for the samples $2 \mathrm{P}$ (phenoxy coating) and $3 \mathrm{~S}$ (polyester coating), respectively.

Table 6. Main compound identified for each of the samples individually.

\begin{tabular}{|c|c|c|}
\hline Samples/ Country & Part of the Tin Can Evaluated & Main Compound Identified \\
\hline \multirow[b]{2}{*}{$1 S$} & Inner Body & Epoxy coating \\
\hline & Inner Cover & Polyester \\
\hline \multirow{3}{*}{$1 \mathrm{P}$} & Inner Bottom & Polyester \\
\hline & Inner Side & Phenoxy coating \\
\hline & Inner Cover & Polyester \\
\hline \multirow{3}{*}{$2 \mathrm{~S}$} & Inner Bottom & Modified phenolic coating \\
\hline & Inner Side & Epoxy coating \\
\hline & Inner Cover & Epoxy coating \\
\hline \multirow{3}{*}{$2 \mathrm{P}$} & Inner Bottom & Polyester \\
\hline & Inner Side & Phenoxy coating \\
\hline & Inner Cover & Polyester \\
\hline \multirow{3}{*}{$3 S$} & Inner Bottom & Epoxy coating \\
\hline & Inner Side & Polyester \\
\hline & Inner Cover & Polyester \\
\hline \multirow{3}{*}{$3 \mathrm{P}$} & Inner Bottom & Polyester \\
\hline & Inner Side & Polyester \\
\hline & Inner Cover & Polyester \\
\hline \multirow{3}{*}{$4 \mathrm{~S}$} & Inner Bottom & Polyester \\
\hline & Inner Side & Polyester \\
\hline & Inner Cover & Polyester \\
\hline \multirow{3}{*}{$4 \mathrm{P}$} & Inner Bottom & Polyester \\
\hline & Inner Side & Phenoxy coating \\
\hline & Inner Cover & Phenoxy coating \\
\hline \multirow{3}{*}{$5 S$} & Inner Bottom & Polyester \\
\hline & Inner Side & Polyester \\
\hline & Inner Cover & Polyester \\
\hline
\end{tabular}


Table 6. Cont.

\begin{tabular}{|c|c|c|}
\hline Samples/ Country & Part of the Tin Can Evaluated & Main Compound Identified \\
\hline \multirow{3}{*}{$5 \mathrm{P}$} & Inner Bottom & Polyester \\
\hline & Inner Side & Polyester \\
\hline & Inner Cover & Polyester \\
\hline \multirow{3}{*}{$6 S$} & Inner Bottom & Phenoxy coating \\
\hline & Inner Side & Polyester \\
\hline & Inner Cover & Polyester \\
\hline \multirow{3}{*}{$6 \mathrm{P}$} & Inner Bottom & Phenoxy coating \\
\hline & Inner Side & Polyester \\
\hline & Inner Cover & Polyester \\
\hline \multirow{3}{*}{$7 S$} & Inner Bottom & Phenoxy coating \\
\hline & Inner Side & Phenoxy coating \\
\hline & Inner Cover & Polyester \\
\hline \multirow{3}{*}{$7 \mathrm{P}$} & Inner Bottom & Polyester \\
\hline & Inner Side & Polyester \\
\hline & Inner Cover & Phenoxy coating \\
\hline \multirow{3}{*}{$8 \mathrm{~S}$} & Inner Bottom & Epoxy coating \\
\hline & Inner Side & Phenoxy coating \\
\hline & Inner Cover & Polyester \\
\hline \multirow{3}{*}{$8 \mathrm{P}$} & Inner Bottom & Epoxy coating \\
\hline & Inner Side & Epoxy coating \\
\hline & Inner Cover & Phenoxy coating \\
\hline \multirow{3}{*}{ 9S } & Inner Bottom & Polyester \\
\hline & Inner Side & Phenoxy coating \\
\hline & Inner Cover & Phenoxy coating \\
\hline \multirow{3}{*}{$10 \mathrm{~S}$} & Inner Bottom & Epoxy coating \\
\hline & Inner Side & Phenoxy coating \\
\hline & Inner Cover & Phenoxy coating \\
\hline \multirow{3}{*}{$11 S$} & Inner Bottom & Epoxy coating \\
\hline & Inner Side & Epoxy coating \\
\hline & Inner Cover & Phenoxy coating \\
\hline
\end{tabular}

S: Spain; P: Portugal.

Phenoxy resin has high molecular weight, a thermoplastic polymer having pendant hydroxyl groups and no oxirane ring [24]. Therefore, a broad peak of the hydroxyl group was observed at $3450.0 \mathrm{~cm}^{-1}$ in the FTIR spectrum, shown in Figure 5a [24]. In Figure 5b the band at $3454 \mathrm{~cm}^{-1}$ is related to stretching vibrations of $\mathrm{OH}$ groups. The bands in the range between $2800-3000 \mathrm{~cm}^{-1}$ correspond to stretching vibrations of $\mathrm{CH}$ groups such as $\mathrm{CH}_{2}$ and $\mathrm{CH}_{3}$ [25]. Weak bands at 1410 and $1462 \mathrm{~cm}^{-1}$ observed in the spectrum of polyester can be assigned to aromatic ring. The strong band at $1269 \mathrm{~cm}^{-1}$ that appears in the spectrum of polyester is due to the twisting vibration of $\mathrm{CH}_{2}$ groups [25]. The similarity between the two spectra is because Phenoxy coating is a thermoplastic polymer derived from BPA $\left(\left(\mathrm{CH}_{3}\right)_{2} \mathrm{C}\left(\mathrm{C}_{6} \mathrm{H}_{4} \mathrm{OH}\right)_{2}\right)$ and epoxy-epichlorohydrin $\left(\mathrm{Cl}-\mathrm{CH}_{2}-\left(\mathrm{C}_{2} \mathrm{H}_{3} \mathrm{O}\right)\right)$ [26]. 


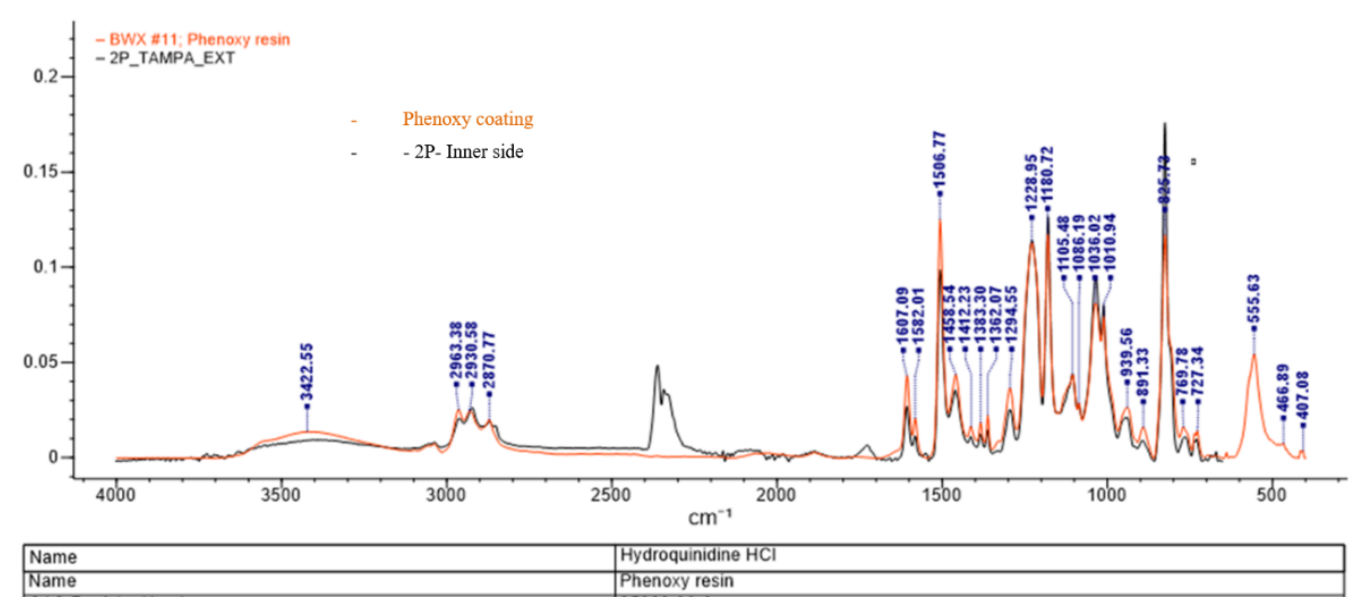

(a)

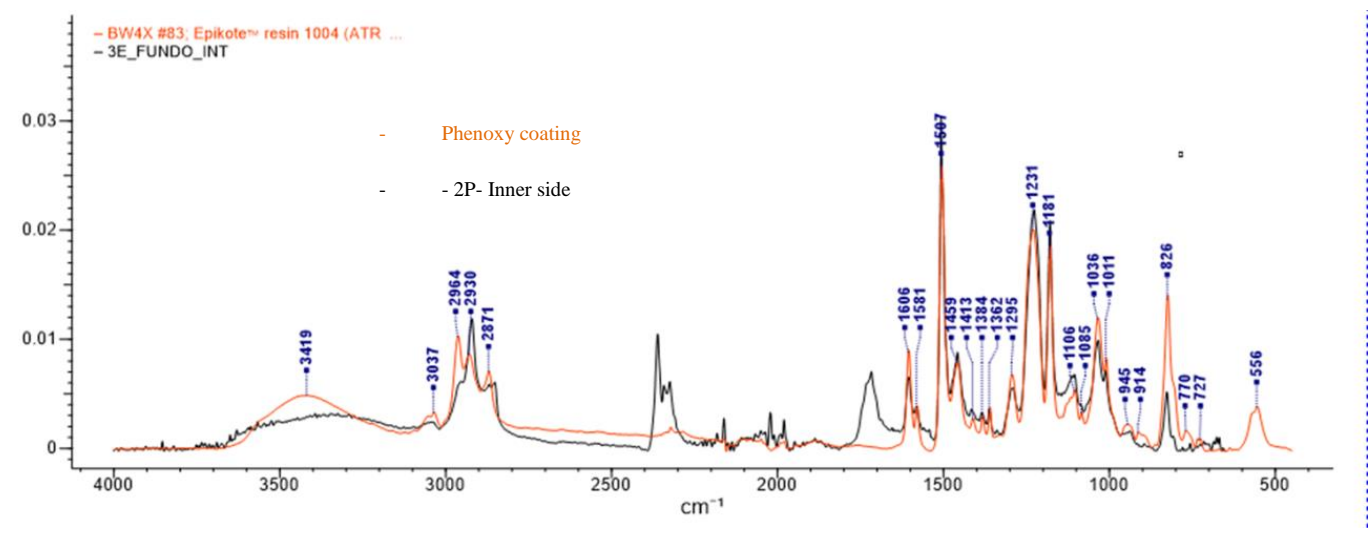

(b)

Figure 5. ATR-FTIR spectra of the: (a) phenoxy coating in the inner side of the sample 2P; (b) polyester coating in the inner bottom of the sample $3 \mathrm{~S}$.

\section{Conclusions}

An analytical method was validated, with success, for the accurate quantitation of Bisphenol A in canned vegetables by high-performance liquid chromatography with fluorescence detection (HPLC-FLD). Good recoveries were obtained showing that method is valid to determine the migration of BPA in these foods. The optimized method was also shown to be precise, and it presents a very low limit of detection $\left(0.005 \mathrm{mg} \mathrm{kg}^{-1}\right)$ and limit of quantification $\left(0.01 \mathrm{mg} \mathrm{kg}^{-1}\right)$. All the samples were analyzed by LC-MS/MS to confirm that BPA was not detected in any of them. The proposed HPLC-FLD method is an excellent tool to monitor the levels of BPA in canned vegetables due to being suitable to ensure compliance with the limit established by actual European Union legislation (SML $0.05 \mathrm{mg} \cdot \mathrm{kg}^{-1}$ ). Its application was demonstrated in real samples. We are aware of the fact that the main limitation of this study is the reduced number of samples. Therefore, in the near future, we are planning to design a study with a wider number of samples. If possible, we will try also to include samples from other countries besides Portugal and Spain, in order to compare the results and be able to reach conclusions on the influence of different the legislation systems in the number of positive samples.

Author Contributions: Conceptualization, R.S. and A.S.-S.; Data curation, A.L.-C.; Formal analysis, F.V. and A.L.-C.; Funding acquisition, A.S.-S.; Investigation, F.V.; Methodology, F.V. and A.C.; Project administration, A.S.-S.; Resources, F.V.; Software, F.V. and A.C.; Supervision, A.S.-S.; Validation, A.L.-C.; Writing-original draft, F.V.; Writing-review \& editing, R.S., A.R.B.d.Q. and M.d.F.V. All authors have read and agreed to the published version of the manuscript. 
Funding: MF Vaz acknowledges FCT, through IDMEC, under LAETA, project UID/EMS/50022/2019. The work was supported by UIDB/00211/2020 with funding from FCT/MCTES through national funds. Fernanda Vilarinho acknowledges National Institute of Health Dr. Ricardo Jorge through the project "Development of methodologies for the evaluation of polymeric food packaging components and determination of their structural and mechanical properties" (2016 DAN 1289). Antía Lestido Cardama is grateful for her grant "Programa de axudas á etapa predoutoral" da Xunta de Galicia (Conselleriía de Cultura, Educación e Ordenación Universitaria). This research was cofounded by the "Consellería de Cultura, Educación e Ordenación Universitaria, Xunta de Galicia," reference number GRC 2019/030.

Conflicts of Interest: The authors declare no conflict of interest.

\section{References}

1. García Ibarra, V.; Sendón, R.; Bustos, J.; Paseiro Losada, P.; Rodríguez Bernaldo de Quirós, A. Estimates of dietary exposure of Spanish population to packaging contaminants from cereal based foods contained in plastic materials. Food Chem. Toxicol. 2019, 128, 180-192. [CrossRef] [PubMed]

2. Sanches-Silva, A.; Freire, J.M.C.; Franz, R.; Paseiro Losada, P.P. Mass transport studies of model migrants within dry foodstuffs. J. Cereal Sci. 2008, 48, 662-669. [CrossRef]

3. Sanches-Silva, A.; Costa, D.; Albuquerque, T.G.; Buonocore, G.G.; Ramos, F.; Castilho, M.C.; Machado, A.V.; Costa, H.S. Trends in the use of natural antioxidants in active food packaging: A review. Food Addit. Contam. Part A 2014, 31, 374-395. [CrossRef] [PubMed]

4. Vilarinho, F.; Sendón, R.; van der Kn, A.; Vaz, M.F.; Silva, A.S. Bisphenol A in food as a result of its migration from food packaging. Trends Food Sci. Technol. 2019, 91, 33-65. [CrossRef]

5. Gugoasa, L.A.D. Review-Electrochemical Sensors for Determination of the Endocrine Disruptor, Bisphenol A. J. Electrochem. Soc. 2020, 167, 37506. [CrossRef]

6. Peng, Y.; Wang, J.; Wu, C. Determination of Endocrine Disruption Potential of Bisphenol A Alternatives in Food Contact Materials Using In Vitro Assays: State of the Art and Future Challenges. J. Agric. Food Chem. 2019, 67, 12613-12625. [CrossRef]

7. Thomson, B.M.; Grounds, P.R. Bisphenol A in canned foods in New Zealand: An exposure assessment. Food Addit. Contam. 2005, 22, 65-72. [CrossRef]

8. Deshwal, G.K.; Panjagari, N.R. Review on metal packaging: Materials, forms, food applications, safety and recyclability. J. Food Sci. Technol. 2020, 57, 2377-2392. [CrossRef]

9. European Commission. Commission Regulation (EU) No 10/2011 of 14 January 2011. on plastic materials and articles intended to come into contact with food. Off. J. Eur. Union 2011, 12, 1-89.

10. Commission Regulation (EU) 2018/213 of 12 February 2018. On the Use of Bisphenol A in Varnishes and Coatings Intended to Come into Contact with Food and Amending Regulation (EU) No 10/2011 as Regards the Use of That Substance in Plastic Food Contact Materials; Official Journal of the European Union: Brussels, Belgum, 2018; pp. 6-12.

11. Barroso, J. Commission Directive 2011/8/EU of 28 January 2011 amending Directive 2002/72/EC as regards the restriction of use of bisphenol A in plastic infant feeding bottles. Off. J. Eur. Union 2011, 50, 11-14.

12. Rykowska, I.; Wasiak, W. Properties, Threats, and Methods of Analysis of Bisphenol a and Its Derivatives. Acta Chromatogr. 2006, 60-780, 21.

13. Sungur, Ş.; Köroğlu, M.; Özkan, A. Determinatıon of bisphenol a migrating from canned food and beverages in markets. Food Chem. 2014, 142, 87-91. [CrossRef] [PubMed]

14. Aristiawan, Y.; Aryana, N.; Putri, D.; Styarini, D. Analytical Method Development for Bisphenol a in Tuna by Using High Performance Liquid Chromatography-UV. Procedia Chem. 2015, 16, 202-208. [CrossRef]

15. Gallo, P.; Di Marco Pisciottano, I.; Fattore, M.; Rimoli, M.G.; Seccia, S.; Albrizio, S. A method to determine $\mathrm{BPA}, \mathrm{BPB}$, and BPF levels in fruit juices by liquid chromatography coupled to tandem mass spectrometry. Food Addit. Contam. Part A 2019, 36, 1-11. [CrossRef] [PubMed]

16. Ballesteros-Gómez, A.; Rubio, S.; Pérez-Bendito, D. Analytical methods for the determination of bisphenol A in food. J. Chromatogr. A 2009, 1216, 449-469. [CrossRef] [PubMed]

17. Nerín, C.; Philo, M.R.; Salafranca, J.; Castle, L. Determination of bisphenol-type contaminants from food packaging materials in aqueous foods by solid-phase microextraction-high-performance liquid chromatography. J. Chromatogr. A 2002, 963, 375-380. [CrossRef] 
18. Cardama, A.L.; Quirós, A.R.-B.; Sendón, R. Analysis of Bisphenol A in Beverages and Food Packaging by High- Performance Liquid Chromatography Food. Nutr. J. 2017, 2017, 4. [CrossRef]

19. Guideline, I.H.T. Note for Guidance on Validation of Analytical Procedures: Text and Methodology (CPMP/ICH/381/95); European Medicines Agency: Amsterdam, The Netherlands, 1995.

20. Guideline, I.H.T. International conference on harmonization. In Proceedings of the Validation of Analytical Procedures: Text and Methodology Q2 (R1), Geneva, Switzerland, 10 November 2005; Volume 11.

21. MacDougall, D.; Crummett, W.B. Guidelines for data acquisition and data quality evaluation in environmental chemistry. Anal. Chem. 1980, 52, 2242-2249. [CrossRef]

22. Poustka, J.; Dunovská, L.; Hajšlová, J.; Holadová, K.; Poustková, I. Determination and occurrence of bisphenol A, bisphenol A diglycidyl ether, and bisphenol F diglycidyl ether, including their derivatives, in canned foodstuffs' from the Czech retail market. Czech J. Food Sci. 2008, 25, 221-229. [CrossRef]

23. Errico, S.; Bianco, M.; Mita, L.; Migliaccio, M.; Rossi, S.; Nicolucci, C.; Menale, C.; Portaccio, M.; Gallo, P.; Mita, D.G.; et al. Migration of bisphenol A into canned tomatoes produced in Italy: Dependence on temperature and storage conditions. Food Chem. 2014, 160, 157-164. [CrossRef]

24. Dixit, V.; Nagpal, A.K.; Singhal, R. Synthesis and Characterization of Phenoxy Modified Epoxy Blends. Malaysian Polym. J. 2010, 5, 69-83.

25. Chukwu, M.; Polytechnic, A.; Ekebafe, L. Effects of Snail Shell as Filler on the Mechanical Properties of Terephthalic Unsaturated polyester Resin. Niger. Res. J. Chem. Sci. 2019, 6, 1-12.

26. Phenoxy Resin (PF). Available online: https://www.corrosionpedia.com/definition/5787/phenoxy-resin (accessed on 31 October 2019).

(C) 2020 by the authors. Licensee MDPI, Basel, Switzerland. This article is an open access article distributed under the terms and conditions of the Creative Commons Attribution (CC BY) license (http://creativecommons.org/licenses/by/4.0/). 